\title{
Socio- Economic and Well Being Status of Aging Population of Sarore Village in Bishnah Tehsil of Jammu District.
}

\author{
Om Raj*, Pushpa Devi \\ Department of Geography, University of Jammu, India.
}

*Corresponding Author: Om Raj, Department of Geography, University of Jammu, India.

\begin{abstract}
This study aims to depict the socio-economic condition of ageing population, their health, family support, financial help from the government schemes, their emotional feelings, and family structure. As the village Sarore is in transition stage due to urbanization and technology of the city region. Concern is also laid on the effect of all such things on their life and family structure.
\end{abstract}

Keywords: Socio-economic, Ageing Population, Urbanization, Emotional feelings

\section{OBJECTIVES}

* To study about the effect of changing social system or family structure on ageing population.

* To study about the health status of ageing population in the village

* To study about the economic condition of old aged population in the village, whether they have saved money or not to secure their life.

* To study about the benefits of government plans on elderly people.

\section{Materials ANd Methods}

Pre field work: This involves library work to get the information about the area in terms of location, relief, flora and fauna, climate and drainage and demographic scenario.

Empirical observation: Empirical observation are made to judge the behavior of people.

Primary data: Here, primary data is the main source of information. The primary data is collected by preparing schedules. The village has almost 800 households and the surveyor has surveyed 50 houses. The primary data is acquired from oral questioning, schedule, and from observation.

Secondary data: Secondary data is acquired from census 2011, Newspapers and other sources.

Methods for data collection: The inspection method has been used for collecting the on field data which means the data collection should primarily be based on direct observation. The data has been collected by directly interacting with each senior citizen and acquired information by questioning him/her.

Quantative methods: The methods like percentage and average to calculate data.

\section{Geographical Personality Of The Study Area}

LOCATION: Sarore is a village located in Bishnah tehsil of the Jammu district of the UT JammuKashmir. The latitude 32.62 and longitude 74.88 are the geo-coordinate of the Sarore. The surrounding nearby villages and its distance from Sarore are Chak Bana $2.9 \mathrm{~km}$, Bishnah $3.4 \mathrm{~km}$, Laswara $6.4 \mathrm{~km}$, Chak Murar $6.4 \mathrm{~km}$ etc. The village is well connected with jammu by metalled road and it is $5 \mathrm{~km}$ away from railway track which joins $\mathrm{j} \& \mathrm{k}$ with rest of the country. The whole area lies in the falling plains of Jammu. The average altitude of the study area is about 420 metres. 


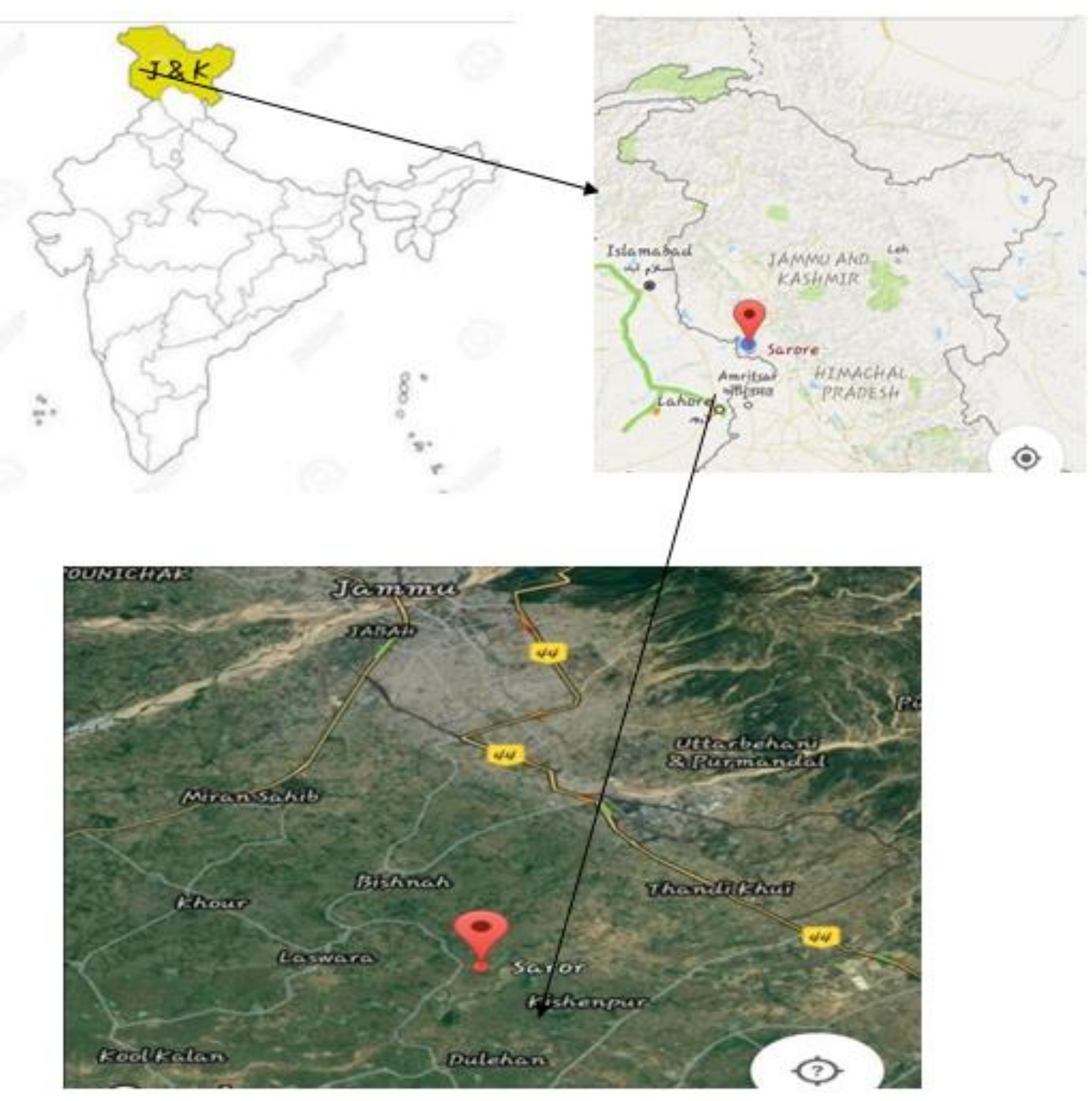

RELIEF: Relief of the area is representation of its topographical expression. The area has a well marked facts of terrain \& undulating topography dissected by a series of seasonal nallas and khads. Sarore has a undulating terrain with deciduous forest and bushes extending from shiwaliks foothills enter into the plain which is locally called as 'khandi'. The area is characterized by numerous torrent dissected soils.

FLORA \& FAUNA: Variety of Flora can be seen in the village which include Berbush, Phulai( Acaciamodesta), Borh, Peepal, Brainker, Ask, Mango, Safeda, Kher, Dhaman, Amla, Bamboo, Sheesham and other ornamental plants etc. The area has once divergence faunal life in the past but with the passage of time due to construction of highway (NH-14) \& Deforestation to meet the requirements of people variety of animal species decreases However the faunal species include animals like cow, Goat, Dog, Sheep, Horse, Donkey etc.

CLIMATE \& DRAINAGE: Climate is the main factor in determining the physical as well as the socio-economic conditions of any area. The village Sarore experience 4 seasons;

$\square$ Summer season

$\square$ Rainy season

$\square$ Winter season

$\square$ Autumn season

The village area is poorly drained. The village is drained by tributaries of the seasonal stream BishramelKhad that flow in the western side of the village. The water level in the tributary rises during rainy season $\&$ vice-versa. 
Socio- Economic and Well Being Status of Aging Population of Sarore Village in Bishnah Tehsil of Jammu District.

DEMOGRAPHIC SCENARIOS: The total population of the village is 4462 out of which 2330 are males \& 2132 are females. The study of the village reveals that $35.36 \%$ of population falls in the adult age group and $33.96 \%$ fall in youth age group \& $10.56 \%$ fall in old age group. The sex ratio of Sarore is higher than both state \& country average which is 915 females per 1000 males. The literacy rate of Sarore is $82.68 \%$ and it is relatively higher in males than females.

As per the social scenario, the village is comprised of maximum concentration of Hindu population \& only a few Muslim Houses are found. Among Hindus some of the distinguish castes are Rajput, SC, Brahmins etc.

LITERACY: The villages Sarore has a large proportion of literates as there are about 3293 persons which are literates out of which 1853 are males and 1440 are females and the rests of the population of the village are illiterates. The proportion of illiterates in the village Sarore are 1169 persons of which 477 are males and 692 are females.

\section{RESULTS AND DisCUSSIONS}

\subsection{Parameters depicting the various aspects of Ageing Population of Sarore village.}

\section{SOCIAL ASPECT}

Table no.1. Age of the respondent

\begin{tabular}{|l|l|l|}
\hline Age & No. of respondents & \%age \\
\hline $59-65$ & 13 & 26 \\
\hline $65-75$ & 33 & 50.76 \\
\hline $75-85$ & 10 & 20 \\
\hline 85 and above & 9 & 14 \\
\hline
\end{tabular}

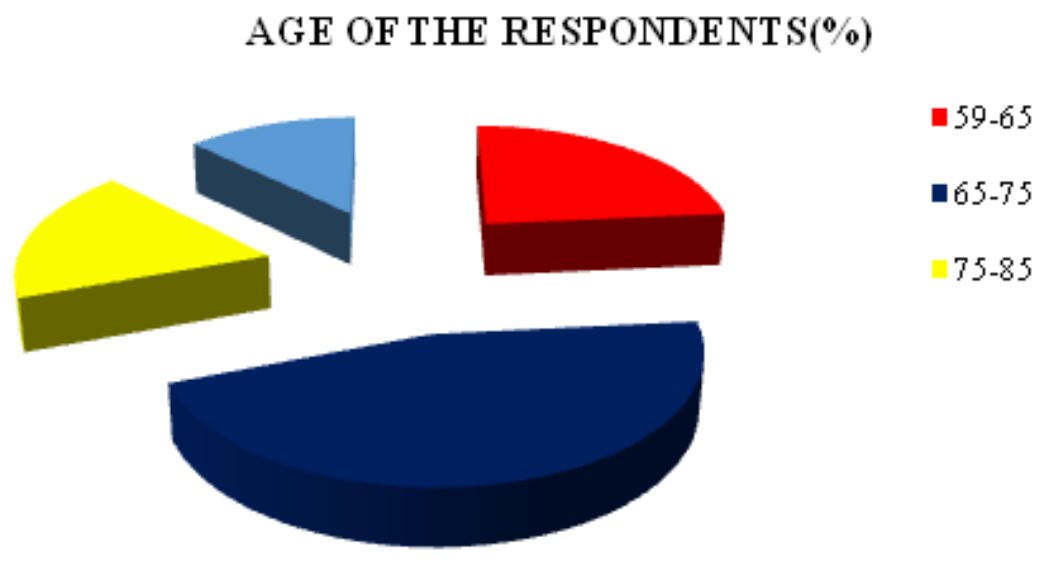

\section{INTERPRETATION:}

From the above data it is clear that the maximum percentage of ageing population is the age group of 65-75years. And the minimum percentage is in the group 85 and above. The 14 percent of senile population above the age of 85 and even it has been observed that out of this 5 percent is above the age of 95 years. This shows that the life expectancy is increasing day by day. Even this 5\% is attributed to the fresh environment and healthy food habits of ageing population as comparison to urban senile population. The village represents a transition from rural to urban so, now the medical facilities are also increasing.

Table no.2. Caste of the respondents

\begin{tabular}{|l|l|l|l|}
\hline S. no. & Caste & No. of families & \%age \\
\hline 1 & SC & 12 & 24 \\
\hline 2 & ST & 2 & 4 \\
\hline 3 & OBC & 6 & 12 \\
\hline 4 & GEN & 30 & 60 \\
\hline
\end{tabular}




\section{CASTE STRUCTURE OF THE AGEING POPULATION(\%)}

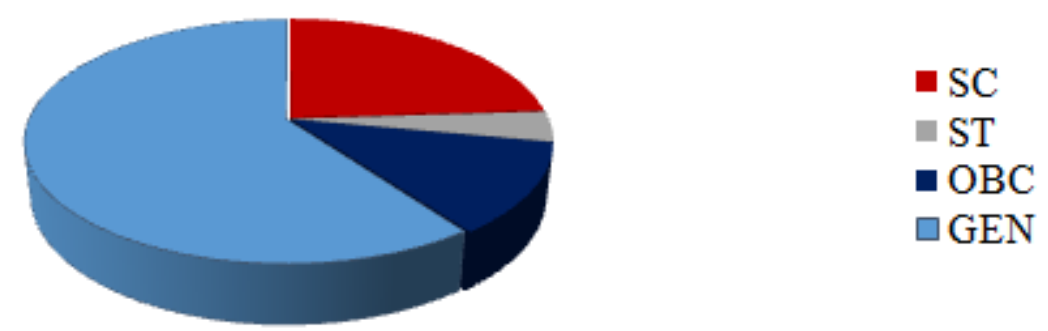

\section{INTERPRETATION:}

From the above table of the caste composition of the ageing population in the village Sarore, it is clear that the maximum concentration is of general category. It contributes to about $60 \%$ to the total surveyed 50 households. While the second rank is occupied by SC population and the ST contributes the lowest percentage of the ageing population. It can be concluded from this that the living conditions of the senile population in the general category is much better as comparison to the other caste structures. That's why the percentage of senile population in general category is more than the other castes. But it also depends upon the total no. of households.

Table no.3. Relationship between caste and type of family structure

\begin{tabular}{|l|l|l|l|l|l|}
\hline S. no & Caste & No. of nuclear family & \% age & No. of joint family & \%age \\
\hline 1 & SC & 10 & 83.33 & 2 & 16.66 \\
\hline 2 & ST & 1 & 50 & 1 & 50 \\
\hline 3 & OBC & 2 & 33.33 & 4 & 66.66 \\
\hline 4 & GEN & 10 & 33.33 & 20 & 66.66 \\
\hline
\end{tabular}

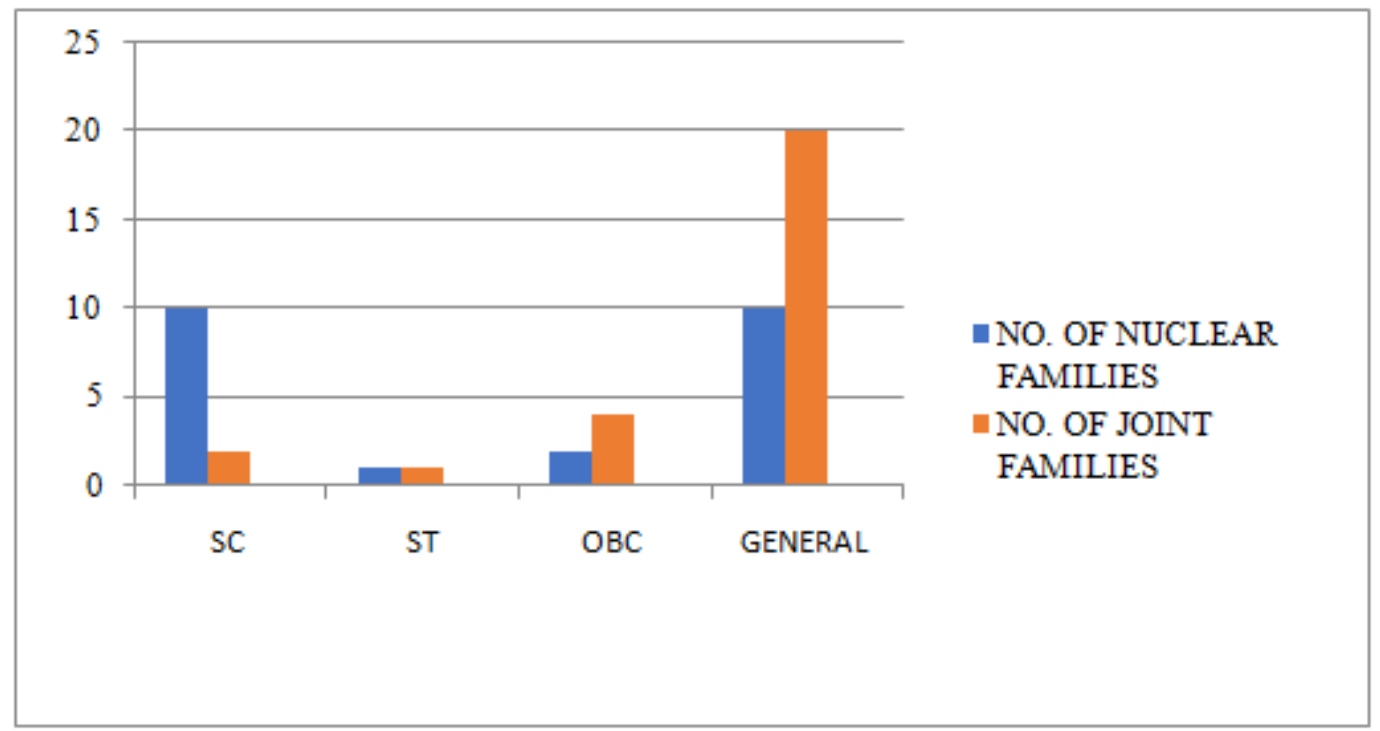

\section{INTERPRETATION:}

The above table depicts the relationship between the caste and the structure of the family. It has been observed that in general category the number of joint families are more as comparison as compare to other castes so the ageing population in the general category is more secure and have better living conditions. But the ST and OBC have more nuclear families so the old aged population in the other castes have more risks of exploitation and plight conditions so they need more care and attention. Such type of structure of families in the other castes is also due to the financial problems.

Table no.4. Number of senior citizens in each household

\begin{tabular}{|l|l|l|l|}
\hline S. no. & No. of senior citizens & No. of respondents & \% age \\
\hline 1 & One & 35 & 70 \\
\hline 2 & Two & 15 & 30 \\
\hline & More than two & 0 & 0 \\
\hline
\end{tabular}




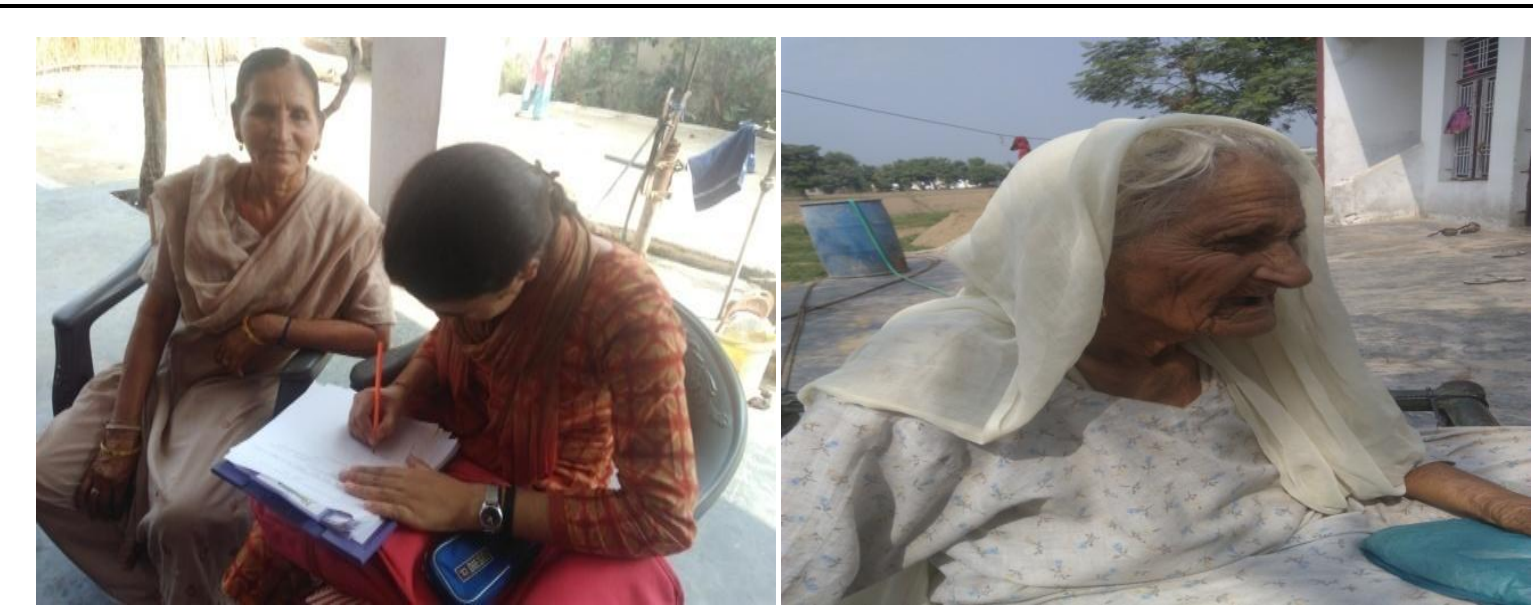

INTERPRETATION:

From the above wheel diagram and the table 3.3 of the no. of senior citizens in each household, it is clear that the maximum households in the village have one senior citizen which accounts to about 70 percent of the total respondents while only 30 percent of the total respondents are couple. From this observation and calculation it is clear that the single senior citizen in the family whether male or female needs more care and attention from the family. They feel more isolation, depressed and thus have dissatisfactory life which ultimately leads to sadness and thus affects the happiness index of the nation.

Table no.5. Number of widows/widower/both in the family

\begin{tabular}{|l|l|l|}
\hline No. of Widows/Widower/Both & No. of Families & \%age \\
\hline Widow & 20 & 40 \\
\hline Widower & 15 & 30 \\
\hline Couple & 15 & 30 \\
\hline
\end{tabular}
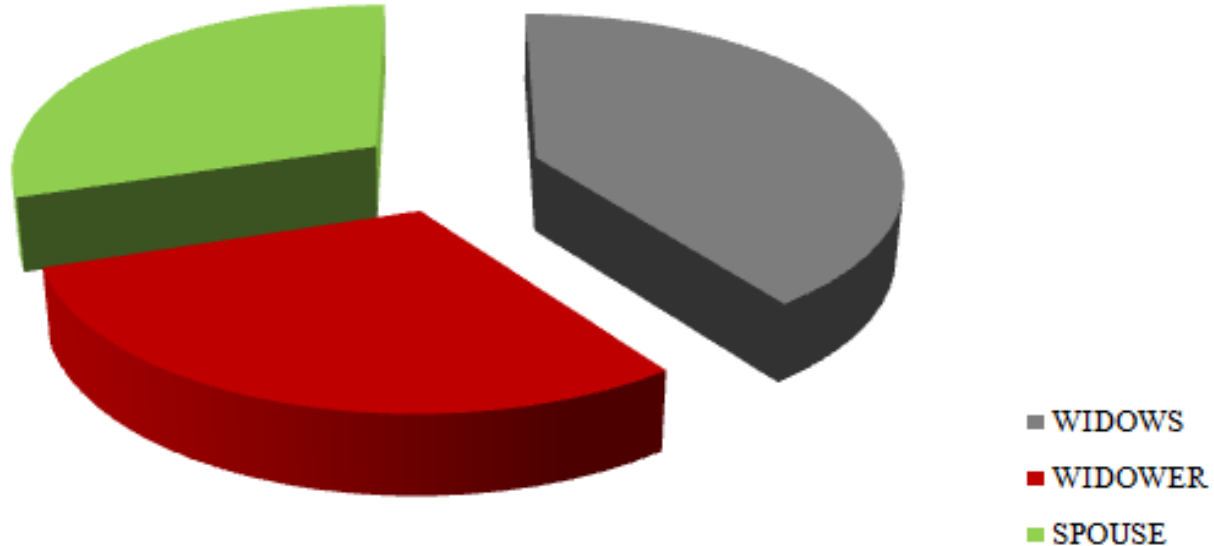

\section{INTERPRETATION:}

As from the previous table we arrived at the conclusion that the maximum percentage of the ageing population in the village is the single senior citizen. But here, in this table we talk in depth whether the single senior citizen is male or female. And it is clear that that the maximum percentage of that single senior citizen is attributed to females that means the widows in the village are more as comparison to widowers. Out of the total 50 families the number of widows is 20 while the widowers are 15. It can also be concluded from this calculation that the life expectancy of females is more as comparison to males and it can be proved that the females are biologically more strong as compared to males. It is also one of the major reason for the plight condition of the women in their old age. Being alone they are also neglected by their children.

Table no.6. Qualification of the Senior Citizens

\begin{tabular}{|l|l|l|l|}
\hline \multicolumn{1}{|c|}{ Qualification } & \%age & Level of Education & \%age \\
\hline Literate & 30.76 & Primary & 75 \\
\hline Illiterate & 53.84 & Secondary & 25 \\
\hline
\end{tabular}




\section{INTERPRETATION:}

From the above education table of the respondents it is clear that the maximum senile population in the village Sarore is illiterate. The literate population in only about $40 \%$ of the total surveyed senile population. Even in the literate population the maximum senior citizens $(70 \%)$ have the primary level of qualification and $25 \%$ have secondary qualification. out of this the literacy among the surveyed females is $0 \%$ while the total literacy among males is $40 \%$. This represents the literacy gap between the males and females in senile population as well as their plight condition. The literacy affects their health and family structure.

Table no.7. Type of family structure

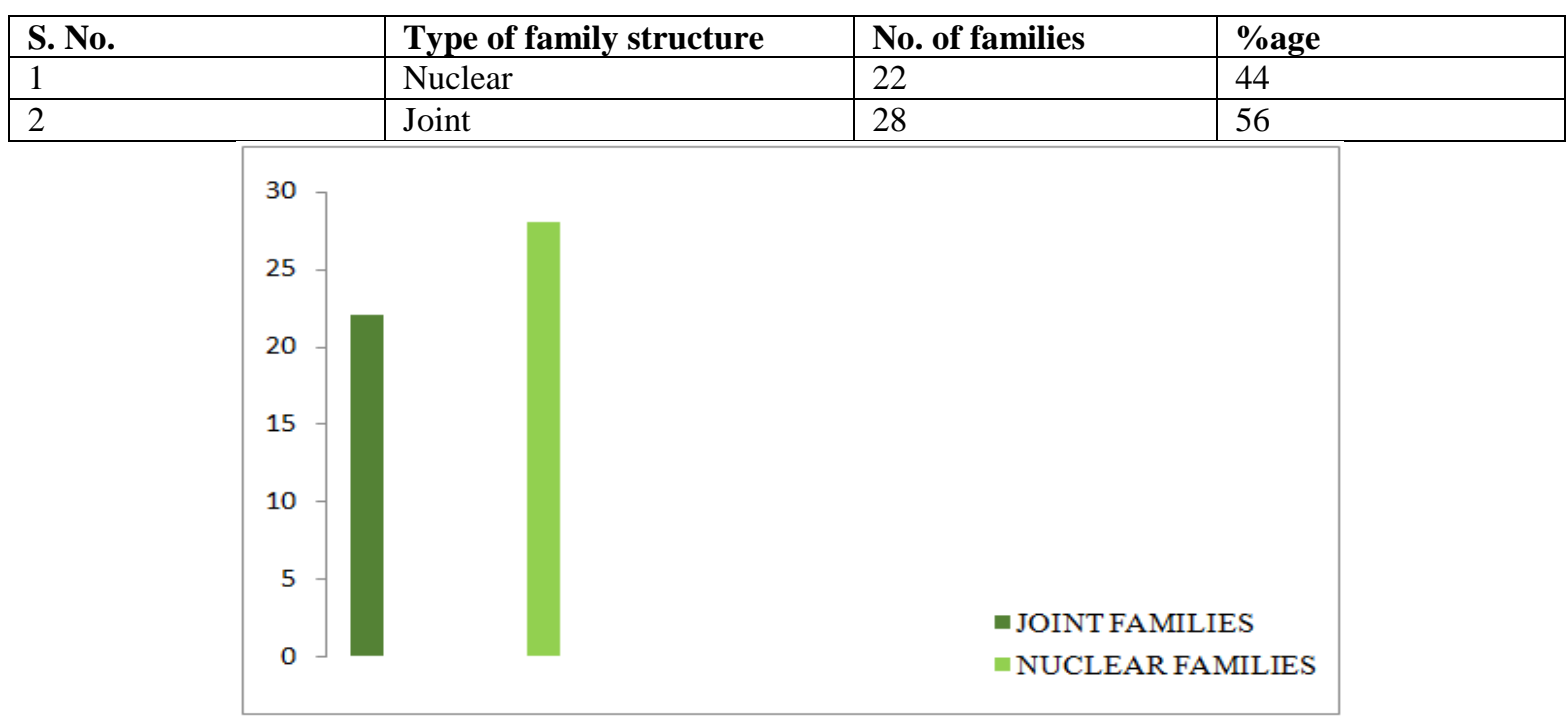

\section{INTERPRETATION:}

Joint family structure is the backbone of the Indian family structure and it is also considered as the social and economic support of ageing population. But now a day the tradition of joint family is disappearing day by day. But still in the Indian villages the joint family system is prevalent it has been observed from the table that even in this village the number of joint families are more as comparison to nuclear. But the percentage of nuclear families is also increasing. Out of the total 50 observed households there are 22 households with nuclear families and the rest 28 have joint families. It can be concluded that the village is in transition phase due to its position in between samba and Jammu.

Table no.8. Senior citizens affected by diseases

\begin{tabular}{|l|l|l|l|l|l|l|}
\hline Disease & No. of Respondent & \%age & Females & \%age & Males & \%age \\
\hline Yes & 45 & 69.23 & 15 & 42.85 & 20 & 66.66 \\
\hline No & 20 & 30.76 & 20 & 57.14 & 10 & 33.33 \\
\hline
\end{tabular}

\section{INTERPRETATION:}

It has been observed from the table that maximum percentage $(69.23 \%)$ of aged population is facing the health problems whether they have chronic or acute or any other disease. While the rest $20 \%$ is free of diseases. It is all because of their better family support and care. But if we compare the health status of male and female we come to the conclusion that the health condition of females is much better as comparison to males. It can be attributed to the labor work, working of males in chimneys.

\section{Health STATUS}

Table no.9. Type of Disease

\begin{tabular}{|l|l|l|}
\hline Type of disease & No. of Respondents & \%age \\
\hline Chronic & 10 & 15.38 \\
\hline Acute & 8 & 12.30 \\
\hline Any other (eyesight problem, body ache) & 40 & 61.53 \\
\hline No & 7 & 10.76 \\
\hline
\end{tabular}




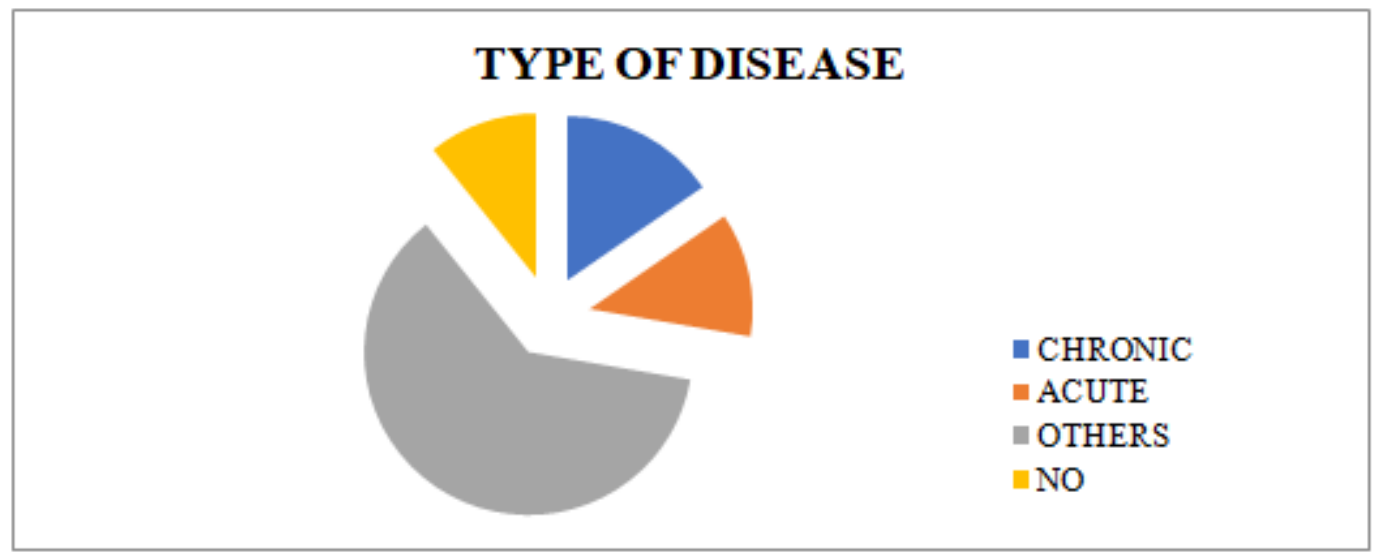

Fig. Type of disease

\section{INTERPRETATION:}

From the collected data and observation through survey, it can be concluded that the maximum percentage of ageing population is suffering from eyesight problem and body ache. These are the common problems due to ageing. The senior citizens above the age of 80 years are generally suffering from body ache and asthma. But no senior citizen is suffering from hereditary disease. A few are suffering from chronic (diabetes and cancer) and few have the problems of BP, heart.

Table no.10. Duration of Health Checkup of Senior Citizens

\begin{tabular}{|c|c|c|}
\hline Duration of health checkups & No. of Respondents & \%age \\
\hline Regular & 20 & 30.76 \\
\hline irregular & 45 & 69.23 \\
\hline 50 & & \\
\hline 45 & & \\
\hline 40 & & \\
\hline 35 & & \\
\hline 30 & & \\
\hline 25 & & \\
\hline 20 & & \\
\hline 15 & & \\
\hline 10 & & \\
\hline 5 & & \\
\hline REGULAR & EGULAR & \\
\hline
\end{tabular}

\section{INTERPRETATION:}

From the above table it is clear that a very few senior citizens go for regular health checkup. About $69.23 \%$ do not go for regular health checkup. It is because of improper care of the family, lack of awareness, economic problems and nucleated families.

Table no.11. Availability of Health Services

\begin{tabular}{|l|l|l|}
\hline Health services & No. of Respondents & \%age \\
\hline Hospital & 50 & 76.92 \\
\hline Dispensary & 10 & 15.38 \\
\hline Medical shop & 5 & 7.96 \\
\hline
\end{tabular}




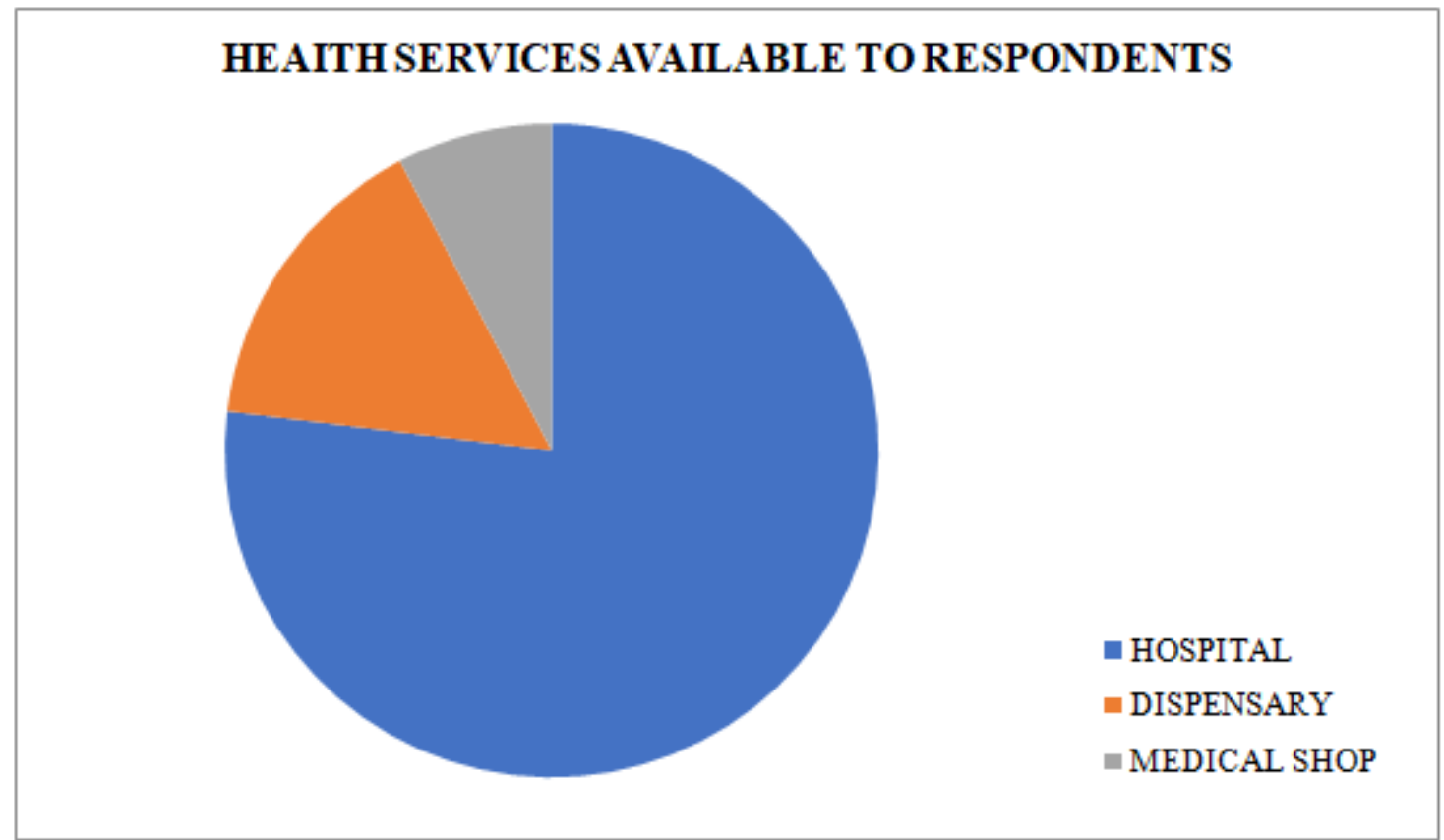

\section{INTERPRETATION:}

From the above table and the pie chart, it is clear that maximum old aged people of the Sarore prefer to for the health checkup in the Bishnah hospital, a few go to jammu hospital and some prefer to checkup in Gandhinagar. It accounts for about $76.92 \%$ of the total respondents. Only $15.38 \%$ of the total respondents prefer to go in dispensary. It means that there are no proper facilities in dispensary. According to some senior citizens the major issue regarding health checkup is that the dispensary provides ayurvedic medicines which the old people don't prefer. Some have complains that they are not properly checked in dispensary. But on a whole I came to the conclusion from the views of all the senior citizens that the dispensary has proper facilities even though it has ayurvedic medicines but the senior citizens are lacking in awareness. And those who are better economically prefer to do their checkups in hospitals and it is only the poor who suffer because of lacking in awareness.

Table no. 12. Hobby or the work done by aged people at home often

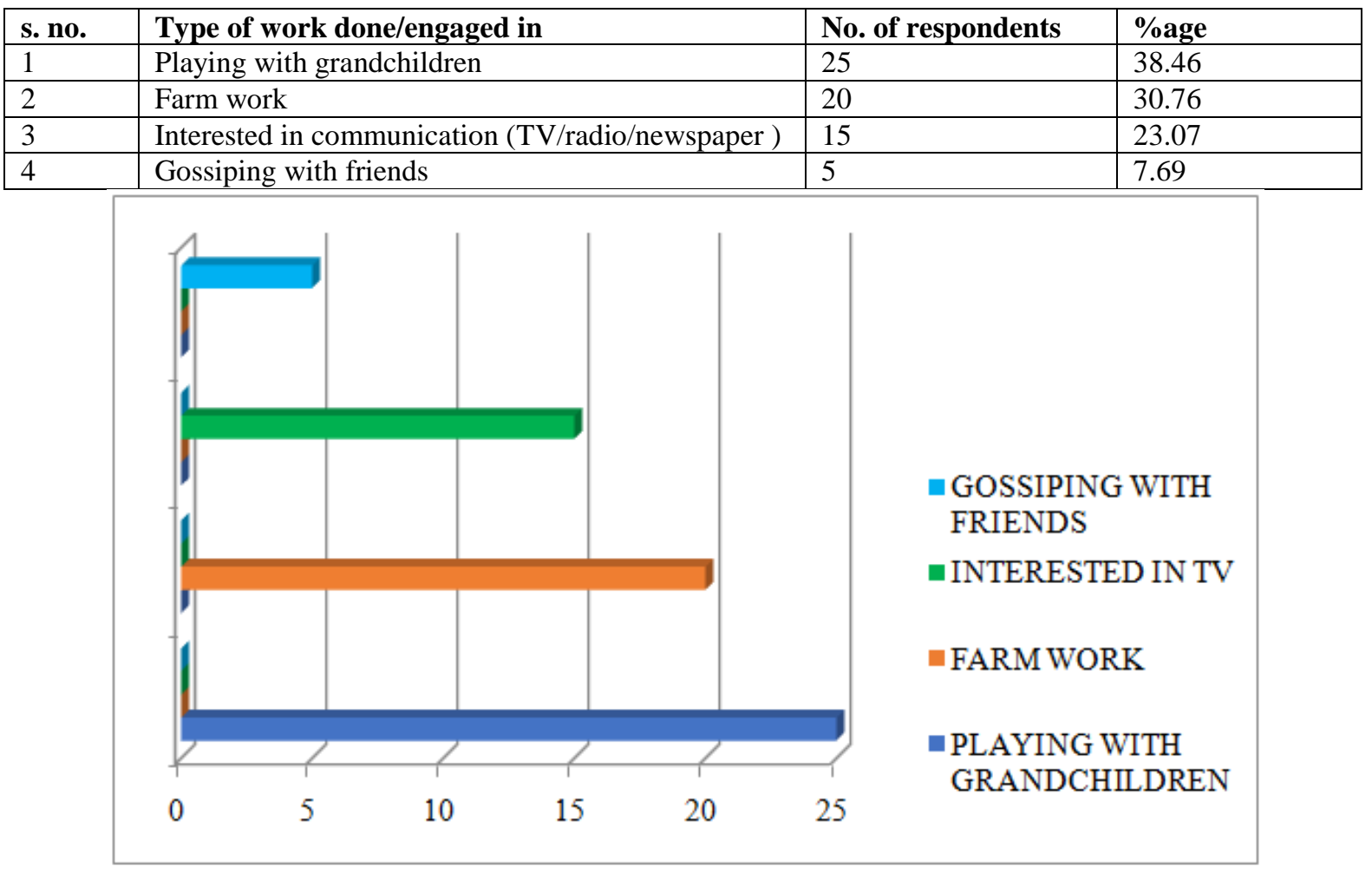


Socio- Economic and Well Being Status of Aging Population of Sarore Village in Bishnah Tehsil of Jammu District.

\section{INTERPRETATION:}

From the above bar graph of the type of work done or the time spend by the senior citizens, has been observed that maximum (38.46) percentage of senile population spends time in playing with their grandchildren, while some spend their time in farm work. The females are generally busy in household activities and form work and males are generally in playing with grandchildren and gossiping with friends.

Table no.13. Views of the ageing population about the changing culture and tradition

\begin{tabular}{|l|l|l|l|}
\hline S. no. & $\begin{array}{l}\text { Views on cultural and traditional } \\
\text { changes }\end{array}$ & No. of respondents & \%age \\
\hline 1 & Good & 35 & 53.84 \\
\hline 2 & Bad & 20 & 30.76 \\
\hline 3 & Need of the hour & 10 & 15.38 \\
\hline
\end{tabular}

\section{INTERPRETATION:}

It is general eye view that the ageing population is not agree with the changing culture and tradition but the reality is different. Maximum of the ageing population is agreed with the changing lifestyle. It contributes to about $53.84 \%$ of the total respondents in the village while $30 \%$ take these as bad changes. But from this observation it can be concluded that the thinking of ageing population in the village Sarore is also changing rapidly with their increasing age. I have personally observed that the senior citizens above the age of 90 are quite satisfied with the modern technology. They thought now things are easily accessible than the time of our youth. And some said change is the law of nature and need of the hour.

Table no.14. Views of ageing population about the young generation's feelings towards old age population

\begin{tabular}{|l|l|l|l|}
\hline S. no. & Thought about new generation & No. of respondents & \%age \\
\hline 1 & Take as burden & 40 & 61.53 \\
\hline 2 & Respect elders & 25 & 38.46 \\
\hline
\end{tabular}

\section{INTERPRETATION:}

The above table is the representation of the views of ageing population about the young generation how senior citizens are taken by young population according to the senior citizens. According to maximum percentage of old aged people they are taken as burden by the youth and a very few think that youth respect aged. It can be depicted from this table that the senile population is being neglected in the villages as well and less cared and respected.

Table no.15. Works often done by ageing population in the village

\begin{tabular}{|l|l|l|l|}
\hline S. no. & Occupation & No. of respondents & \%age \\
\hline 1 & Retired & 15 & 23.07 \\
\hline 2 & Working & 5 & 7.69 \\
\hline 3 & No work & 45 & 69.23 \\
\hline
\end{tabular}

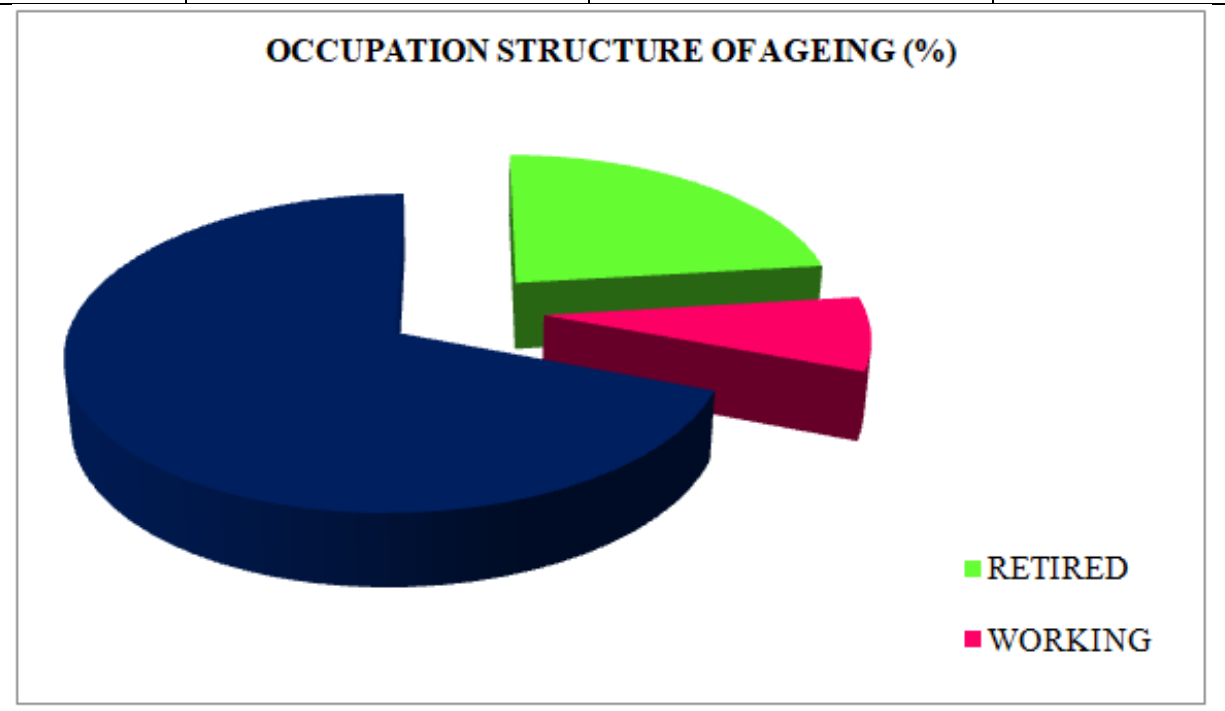


Socio- Economic and Well Being Status of Aging Population of Sarore Village in Bishnah Tehsil of Jammu District.

\section{INTERPRETATION:}

From the above table it is clear that maximum percentage of aged population were unemployed and generally prefer agriculture, farm work, and household activities. About $23 \%$ of the total respondents are retired from the Indian army and a very few or negligible were involved in private jobs in their youth.

Table no.16. Views of the ageing population regarding the saving of money for their old age necessities

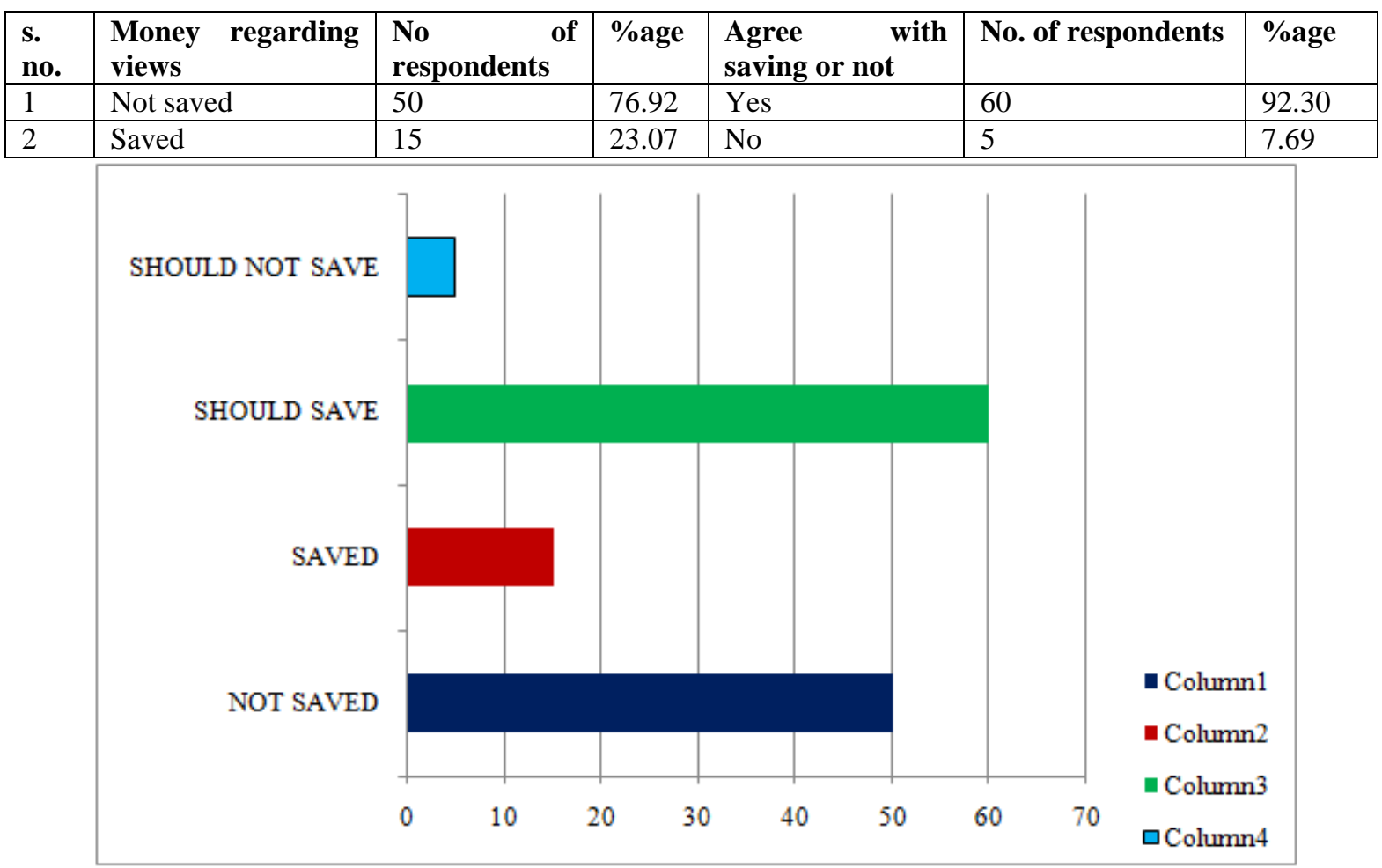

\section{INTERPRETATION:}

As it is a well known fact that money is the most important security of man in old age. It has been observed that those senior citizens have given everything to their children are often being left by their children. Keeping this in mind, the question regarding money is asked to the aged people in the village. It has been observed that about $7 \%$ of the total respondents have saved money and rest $73 \%$ haven't saved. The reason behind not saved is their poor economic condition and laborer, agricultural work and because of unemployment. Money is saved by those who have pension and are retired army men. It has been asked to them whether money should be saved on not for old age. About $92 \%$ of the attended senior citizens have the views that money should be saved by senior citizen in order to secure their old age. And a very few think there is no to save, they said it because of their satisfied life and very supportive family. But those who said that money should be saved thought quite rationally and said everyone wants to save but can't because of weak financial background. Even government has initiated a number of schemes but lack of awareness and corruption can't make things good.

Table no.17. Views of senior citizens about the differences in their living styles in rural and urban areas

\begin{tabular}{|l|l|l|l|}
\hline S. no. & Rural ageing pop. is more cared by their children than urban & No. of respondents & \%age \\
\hline 1 & Yes & 60 & 92.30 \\
\hline 2 & No & 5 & 7.69 \\
\hline
\end{tabular}

\section{INTERPRETATION:}

It has been observed from the table that about $92,3 \%$ of the ageing population is agree with the statement that the living condition, care and attention paid by their families to the aged population is much better in rural areas as comparison to villages. But a few have the views that both urban and rural areas have the same condition. The youth in the villages is also competing the urban youth in terms of leaving their parents in old age. But it can be concluded from the above table that the ageing population in the village Sarore is well satisfied with their children but exceptions are always there. 
Socio- Economic and Well Being Status of Aging Population of Sarore Village in Bishnah Tehsil of Jammu District.

Table no.18. Views of old aged population about the effect of ageing population on the economy of a nation

\begin{tabular}{|l|l|l|l|l|}
\hline S. no. & Economy and ageing population & Reply of respondent & No. of respondents & \%age \\
\hline 1 & Burden & Yes & 45 & 69.23 \\
\hline 2 & Not burden & No & 10 & 15.38 \\
\hline 3 & No answer & No answer & 5 & 7.69 \\
\hline
\end{tabular}

INTERPRETATION:

As we all know that the rapidly increasing ageing population is not only the issue of major concern in developed countries it is also attracting the attention of social thinkers and policy makers in developing countries like India. As Kerala and other developed southern Indian states are facing the problem of ageing population because of selective out migration and better health facilities. So, now ageing population is becoming a burden on the nation's economy. A similar question has been asked to the ageing population, maximum of the aged people agree with this that they are burden on nation. A few of them mostly the ex-servicemen are not agree with it. Some said that nation should find such ways that they may use their ageing population, so that neither the ageing population feel isolated nor nation have the burden of it.

Table no.19. The feelings or the wishes of old aged population that they think to be fulfilled.

\begin{tabular}{|l|l|l|l|}
\hline s. no. & Last wishes & No. of respondents & \%age \\
\hline 1 & To visit any pilgrimage & 10 & 15.38 \\
\hline 2 & Spend time with family & 50 & 76.92 \\
\hline 3 & Others & 5 & 7.6 \\
\hline & WISHES OF THE SENOIR CITIZENS(\%)
\end{tabular}

\section{INTERPRETATION:}

It is clear from the above pie diagram that the maximum proportion of old aged population have the wishes to spend maximum time with their family members. More specifically, that we have observed that maximum senior citizens in the village want to spend time with their grand children and prefer joint family. Some also want to visit any pilgrimage. But maximum have the views that family is the biggest pilgrimage for an old person.

Suggestions: As we all know that senior citizens are the live literature, history, live laboratories of proved experiments for the young generation. Children that are wasting their childhood in playing games on TV and Mobile phones should devote their time under supreme guidance of aged people in their home. In this way children remain happy and the busy parents are also able to protect their children from bad habits of social media and from their physical, mental and health effects and diseases can be reduced. Government has taken certain initiative but there is the need of doing more initiative with the increasing population to engage them in some work that make them happy, secure their social security and benefit nation. Also there is need of proper management of the funds provided by the government to the aged population and their proper enquiry. 


\section{CONCLUSION}

From the above calculation, observation and discussion, we came to the conclusion that the village has better socio-economic condition of ageing population. But there is a sharp demarcation in the socio-economic condition on the basis of caste. It can be concluded from the observation that it's only the ageing population in the general category that have less complains but the senior citizens in other caste have both social as well as economic problems. The major concern in the village is the increasing widow population. And even a very few out of the total surveyed two -three are getting widow pension. So, there is the need to spread awareness about widow pension and need to register all widows and provide them pension. They have more economic expectation from the government. The ageing population is quite dissatisfied with the changes in the family structure in the society. It has been observed that in the village the senior citizens in the joint families are more satisfied and happy than the nucleated. It's a general view of integration of the whole family of ageing population. Socially, all are better but maximum of the ageing population have the economic problem which is directly related to their health, food, satisfaction and happiness and they have the hunger of only respect and affection from their children. Their message to the new generation was to serve humanity, Never forget human values, work hard and maintain discipline. They are quite dissatisfied with the increasing use of mobile phone and other social media because it all leads to neglect to them by their children as well as grandchildren. About the concept of ageing population and increasing burden on national economy all are agreed with it but they are still willing to support nation.

\section{ACKNOWLEDGEMENT}

The author is highly thankful to people of village Sarore which provide the requisite information for accomplishing this field investigation.

\section{LiTERATURE CiTED}

[1] Kohli, A.S. Social Situation of the Aged in India, Anmol Publications Pvt.Ltd., New Delhi 1996.

[2] Subrahmanya, R.K.A. (1994) Income Security for the Elderly in India. BOLD. Vol2, No.4, p. 28.

[3] Jhilam Rudra De. "Management of Old Age - A Critical Problem in Indian Perspective across Culture and Time," (Unpublished Paper).

[4] Sivamurthy, M. and Wadakannavar, A. R. "Care and Support for the Elderly Population in India: Results from a Survey of the Aged in Rural North Karnataka, India," (Unpublished paper submitted to the IUSSP General Population Conference Held at Salvador, Brazil, 18-24, Aug. 2001).

[5] Leena, A, Ashok, K., Padma, M., Kamat, V., and Kamat, A. "Health and Social Problems of the Elderly: A Cross-Sectional Study in Udupi Taluk, Karnataka," Indian Journal of Community Medicine, Vol. 34, Issue 2, April 2009.

[6] Kulkarni, J., Bharati,V., and Rekhade, N. "Adjustmental Problems of Old Persons,” Shodh, Samiksha aur Mulyankan, Vol. II Issue 9-10,Oct-Nov., 2009.

[7] Behara, N.K. and R.P. Mohanty (2005). Aged in Changing Social System and their Problems. New Delhi: Discovery Publishing House.

[8] Bhatia, H.S (1983) Ageing and Society: A Sociological Study of Retired Public Aspects of Ageing in India. New Delhi: National Institute of Health and Family Welfare.

Citation: Om Raj, Pushpa Devi. "Socio- Economic and Well Being Status of Aging Population of Sarore Village in Bishnah Tehsil of Jammu District." International Journal of Research in Geography. vol 7, no. 2, 2021, pp. 17-28 doi: http://dx.doi.org/10.20431/2454-8685.0702002.

Copyright: (C) 2021 Authors. This is an open-access article distributed under the terms of the Creative Commons Attribution License, which permits unrestricted use, distribution, and reproduction in any medium, provided the original author and source are credited. 